\title{
Dual-slot based Rectangular Microstrip Antenna for WiMAX, WCS and C-band Satellite Applications
}

\author{
Surjit Singh ${ }^{1}$, Amrit Kaur ${ }^{2}$ \\ M.Tech Student, ECE, Baba Banda Singh Bahadur Engineering College, Fatehgarh Sahib, India ${ }^{1}$ \\ Assistant Professor, ECE, Baba Banda Singh Bahadur Engineering College, Fatehgarh Sahib, India ${ }^{2}$
}

\begin{abstract}
A dual-band rectangular microstrip antenna (RMSA) with two slots for wireless applications such as WiMAX (2.3 GHz), WCS (Wireless Communications Service- 2.305-2.32 GHz) and C-band (4.6480-4.8170 GHz) satellite applications is presented. The graphs for return loss, 3D radiation pattern and VSWR are obtained using Ansoft HFSS 13.0. The obtained results are satisfactory.
\end{abstract}

Keywords: Dual-band RMSA, WiMAX, WCS, C-band.

\section{INTRODUCTION}

In the modern age of wireless communication, an antenna plays a very significant role. The antennas should be compact to get constructed into the wireless devices and should support multi-band frequency applications while having good performance characteristics such as gain, bandwidth, return loss etc. The Microstrip Antennas (MSA) are the most commonly used antennas for compact wireless devices due to its conformal nature, light weight and easy manufacturing. But low bandwidth and gain are the major limitations of MSA [1].The MSA generally consists of a radiating metallic patch fabricated over the ground plane with the dielectric substrate included between them. Fig. 1 shows the basic geometry of a MSA.

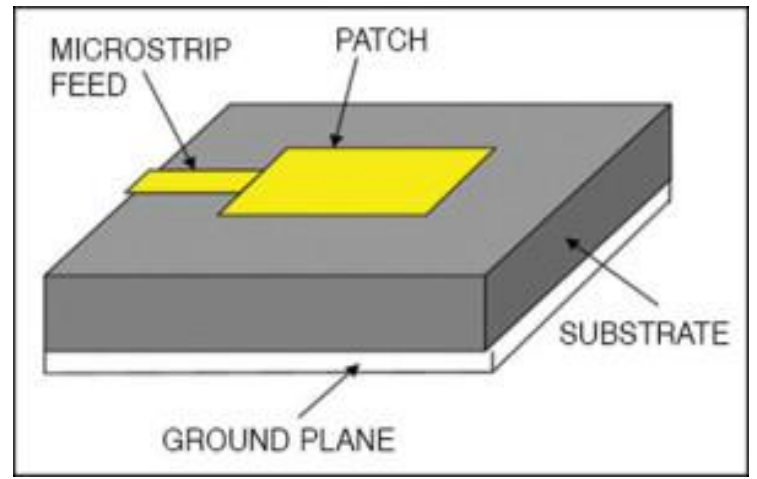

Fig. 1 Basic geometry of MSA [2]

There are various shapes and sizes of a MSA are available such as rectangular, square, circular, triangular and elliptical etc., from which the circular, square and Rectangular MSA are mostly preferred [1]. There are various feeding methods by which the MSA is fed such as Microstrip line method,Coaxial probe feed method, Aperture-coupled and Proximitycoupled method. The most easy and suitable type of feeding method is Coaxial probe method [3]. The MSA can be operated for multi-bandfrequency applications by using stubs and slots into the top patch element and ground plane [46]. A rectangular patch antenna for $2.4 \mathrm{GHz}$ with return loss of $-38 \mathrm{~dB}$ is presented in [7]. The design of antenna is based on FR4 substrate. The proposed antenna has a gain of $3.954 \mathrm{~dB}$ and suitable for wireless applications such as WLAN, Wi-Fi etc. A dual-band slotted rectangular MSA for $1.90 \mathrm{GHz}$ and $2.59 \mathrm{GHz}$ frequencies with return loss of $9.56 \mathrm{~dB}$ and $-12.32 \mathrm{~dB}$ is presented in [8]. The design is based on Neltec NX 9240 epoxy substrate. A rectangular MSA with $\mathrm{H}$ and $\mathrm{T}$ shaped slots for $2.4 \mathrm{GHz}$ is presented in [9] with gain of $8.21 \mathrm{~dB}$ and $6.90 \mathrm{~dB}$ respectively. The proposed antenna can be used for WiMAX, Wi-Fi and Digital Multimedia Broadcasting (DMB) applications.

In this paper, a rectangular coaxial-fed MSA with two slots (vertical and horizontal) are presented for dual-band operation $(2.3 \mathrm{GHz}$ and $4.7 \mathrm{GHz})$. The proposed antenna can cover the WiMAX $(2.3 \mathrm{GHz})$, WCS from 2.305-2.32 GHz and C-band (4.6480-4.8170 GHz) satellite applications. 


\section{DESIGN AND METHODOLOGY OF PROPOSED ANTENNA}

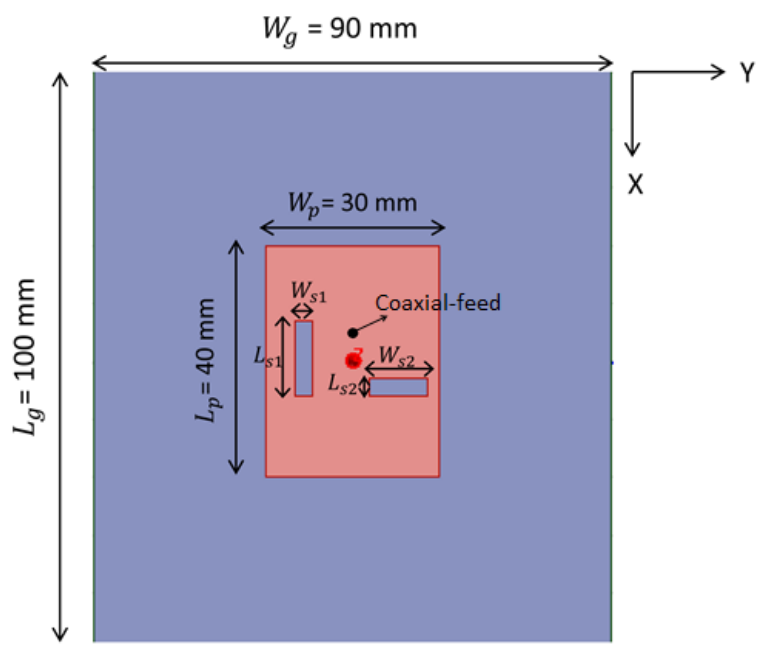

Fig. 2 Proposed antenna top view

The top view of proposed antenna is shown in Fig. 2.It consists of a rectangular top patch of dimensions $L_{p} \times W_{p}$, a ground plane of dimensions $\mathrm{L}_{\mathrm{g}} \times \mathrm{W}_{\mathrm{g}}$, a Rogers RT/duroid 5880 substrate of height $\mathrm{h}=3.2 \mathrm{~mm}$, two rectangular slots of dimensions $\mathrm{L}_{\mathrm{s} 1} \times \mathrm{W}_{\mathrm{s} 1}$ and $\mathrm{L}_{\mathrm{s} 2} \times \mathrm{W}_{\mathrm{s} 2}$ respectively and a coaxial feed. The details of all dimensions of the proposed antenna are given in Table I. The design procedure of patch antenna has been followed by using the steps described in [1] and given by the flowchart in Fig. 3 as:

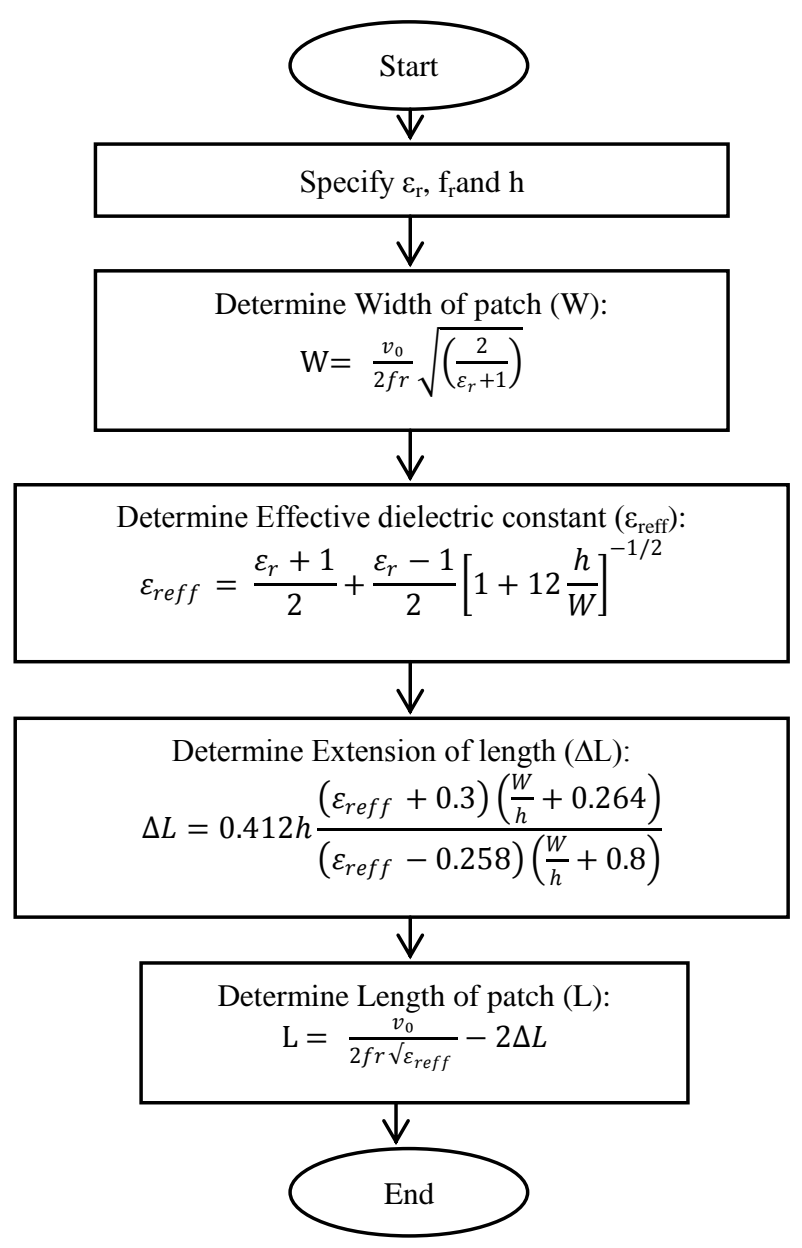

Fig. 3 Flowchart for design of patch antenna 
Here, $\varepsilon_{\mathrm{r}}, \mathrm{f}_{\mathrm{r}}, \mathrm{h}$ and $\mathrm{v}_{0}$ are the dielectric constant of substrate, resonant frequency, height of substrate and free-space velocity of light respectively. The calculated parameters of antenna are optimized for the desired results.

The proposed design consists of one vertical slot and one horizontal slot inserted into the top patch as shown in Fig. 2. These slots are used for dual-band operation and gain enhancement. The simple patch without any slot resonates at 2.37 $\mathrm{GHz}$ frequency. The first vertical slot introduces the resonant frequency of $4.8 \mathrm{GHz}$ into the structure. The second horizontal slot is used to reduce the mismatch loss of $1^{\text {st }}$ frequency band which occurs at $2.4 \mathrm{GHz}$ and introduces a resonant frequency of $2.3 \mathrm{GHz}$ with improved return loss.

TABLE I DIMENSIONS OF PROPOSED ANTENNA

\begin{tabular}{|l|l|l|l|}
\hline Dimension & Value (mm) & Dimension & Value (mm) \\
\hline $\mathrm{L}_{\mathrm{g}}$ & 100 & $\mathrm{~L}_{\mathrm{s} 1}$ & 13 \\
\hline $\mathrm{W}_{\mathrm{g}}$ & 90 & $\mathrm{~W}_{\mathrm{s} 1}$ & 3 \\
\hline $\mathrm{L}_{\mathrm{p}}$ & 40 & $\mathrm{~L}_{\mathrm{s} 2}$ & 3 \\
\hline $\mathrm{W}_{\mathrm{p}}$ & 30 & $\mathrm{~W}_{\mathrm{s} 2}$ & 10 \\
\hline Substrate details- Rogers RT/duroid 5880 \\
$\begin{array}{l}\text { Length }=100 \mathrm{~mm} \\
\text { Width }=90 \mathrm{~mm}\end{array}$ & $\begin{array}{l}\text { Height }(\mathrm{h})= \\
3.2 \mathrm{~mm}\end{array}$ & $\begin{array}{l}\text { Dielectric } \\
\text { constant }\left(\varepsilon_{\mathrm{r}}\right)=2.2\end{array}$ & $\begin{array}{l}\text { Dielectric loss tangent } \\
(\delta)=0.0009\end{array}$ \\
\hline Feed details- Coaxial probe \\
\hline \begin{tabular}{l} 
inner conductor radius \\
\hline
\end{tabular}
\end{tabular}

\section{III.RESULTS AND DISCUSSIONS}

\section{A. Return Loss}

The graph of return loss values against frequency values are shown in Fig. 4.

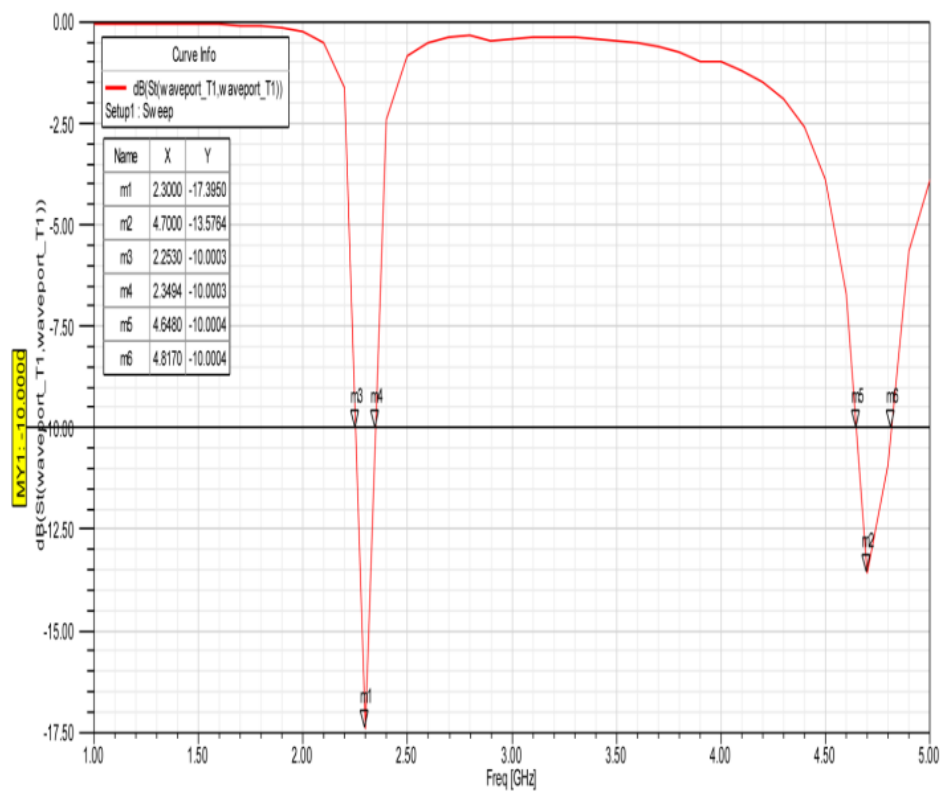

Fig. 4 Return loss vs. frequency graph

The proposed antenna resonates at $2.3 \mathrm{GHz}$ with Band $1(2.2530-2.3494 \mathrm{GHz})$ and $4.7 \mathrm{GHz}$ with Band 2 (4.6480$4.8170 \mathrm{GHz}$ ) with impedance bandwidth $(-10 \mathrm{~dB})=96.4 \mathrm{MHz}$ and $169 \mathrm{MHz}$ respectively. The obtained values of return loss for $2.3 \mathrm{GHz}$ and $4.7 \mathrm{GHz}$ are $-17.3950 \mathrm{~dB}$ and $-13.5764 \mathrm{~dB}$ respectively. The antenna can support wireless applications such as WiMAX $(2.3 \mathrm{GHz})$, WCS $(2.305-2.32 \mathrm{GHz})$ and Satellite C-band (4.6480-4.8170 GHz).

\section{B. VSWR}

The results for VSWR are shown in Fig. 5. The VSWR values are 1.3121 for $2.3 \mathrm{GHz}$ and $1.53 \mathrm{for} 4.7 \mathrm{GHz}$ respectively. 


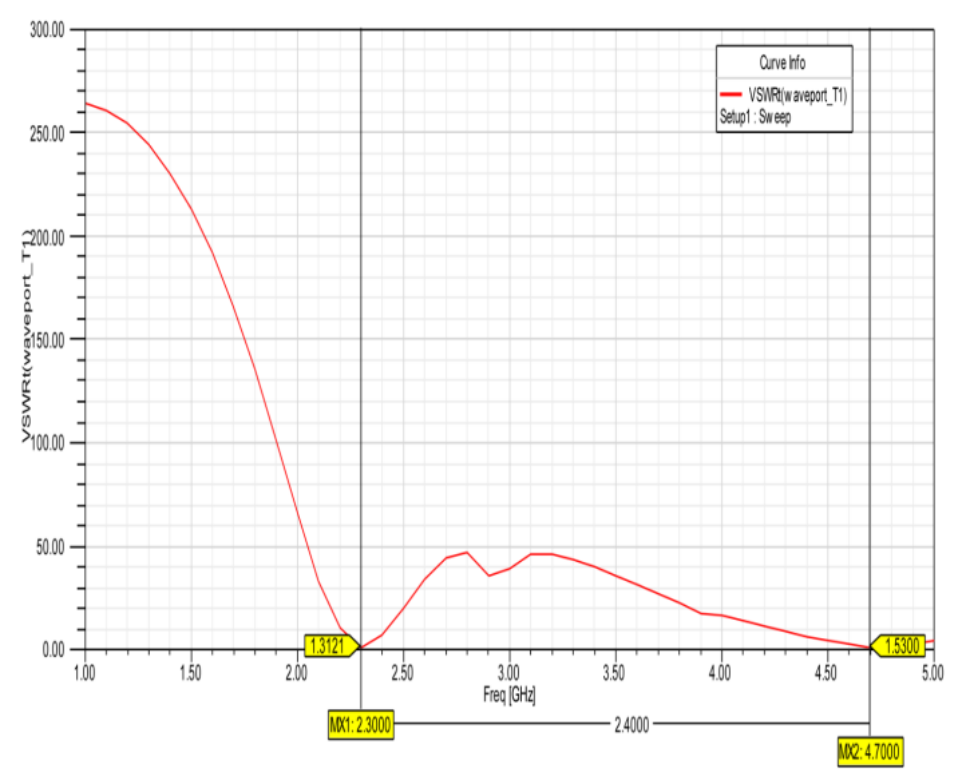

Fig. 5 VSWR vs. frequency graph

C. 3D Radiation Pattern

The three-dimensional radiation pattern with gain $(\mathrm{dB})$ of proposed antenna is shown in Fig. 6 and Fig. 7.
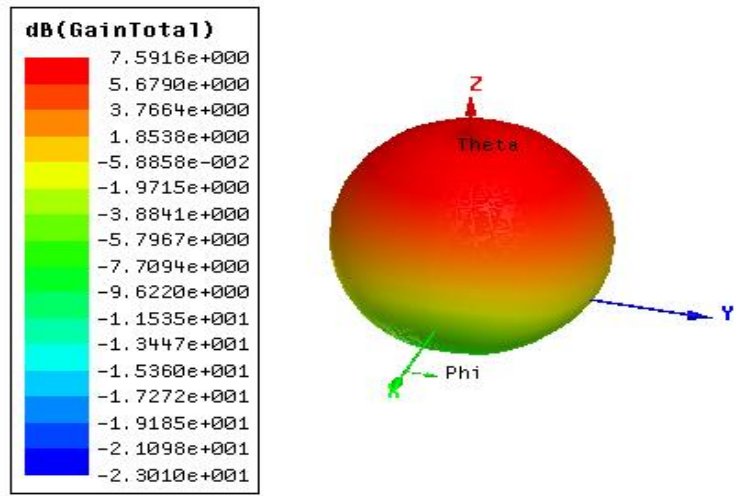

Fig. $63 \mathrm{D}$ radiation pattern for $2.3 \mathrm{GHz}$
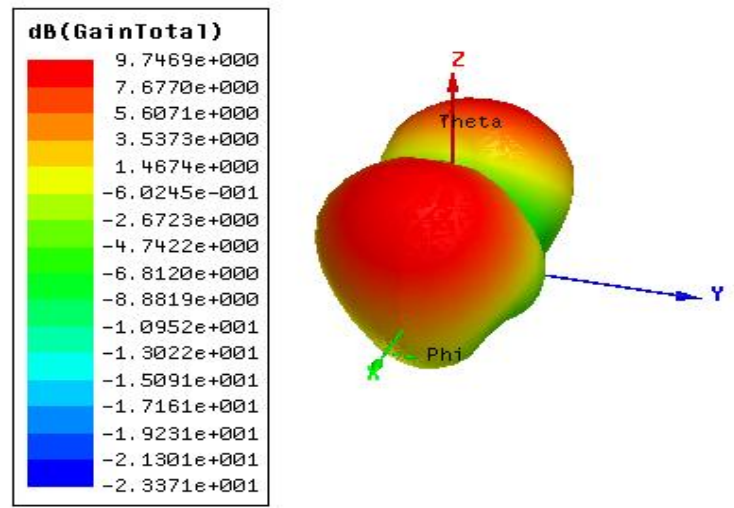

Fig. $73 \mathrm{D}$ radiation pattern for $4.7 \mathrm{GHz}$

From Fig. 6 and Fig. 7, it is shown that radiation pattern of antenna is quite directional for $2.3 \mathrm{GHz}$ and nearly omnidirectional for $4.7 \mathrm{GHz}$ frequency. The maximum value of gain for $2.3 \mathrm{GHz}$ and $4.7 \mathrm{GHz}$ is $7.5916 \mathrm{~dB}$ and $9.7469 \mathrm{~dB}$ which is more than as depicted in [10]. 


\section{IV.CONCLUSION}

A dual-slotted rectangular patch antenna is presented in this paper. The antenna resonates at $2.3 \mathrm{GHz}$ and $4.7 \mathrm{GHz}$ frequency with return loss of $-17.3950 \mathrm{~dB}$ and $-13.5764 \mathrm{~dB}$ respectively. The gain of antenna at $2.3 \mathrm{GHz}$ and $4.7 \mathrm{GHz}$ is $7.5916 \mathrm{~dB}$ and $9.7469 \mathrm{~dB}$ respectively, which is more than as depicted in [10]. The antenna is useful for WiMAX, WCS and C-band satellite applications.

\section{REFERENCES}

[1] Constantine A. Balanis, "Microstrip Antennas," in Antenna theory:analysis and design, $2^{\text {nd }}$ ed. Singapore: Wiley, 2001, ch. 14, pp. 722-735.

[2] [Online].Available:http://electronicsforu.com/technology-trends/microstrip-antenna applications [Accessed: 10-April-2017].

[3] KomalJaiswal, Mukesh Kumar, A.K. Jaiswal, Anil Kumar and RohiniSaxena, "Design and Analysis of E- Patch Microstrip Antenna for S Band,"International Journal of Current Engineering and Technology, Vol.4, No.3, pp. 1741-1744, June 2014.

[4] PriyanarayanMisra and AmareshTripathy, "Triple Band Planar Antenna for Wireless Communication," International Journal of Computer Applications, Vol. 48, No. 23, pp. 28-30, June 2012.

[5] PreetKanwalKaur, Ramanjeet Singh, " Rectangular Shaped Microstrip Antenna for Triple-band Operation,” International Journal of Advanced Research in Computer and Communication Engineering, Vol. 4, Issue 3, pp. 233-236, March 2015.

[6] SamiranChatterjee, Santosh Kumar Chowdhury, ParthaPratimSarkar, DebasreeChandaSarkar, "Compact microstrip patch antenna for microwave communication,” Indian Journal of Pure \& Applied Physics, Vol. 51, No. 11, pp. 800-807, Nov. 2013.

[7] Pradeep Kumar, Neha Thakur, AmanSanghi, "Micro strip Patch Antenna for 2.4 GHZ Wireless Applications," International Journal of Engineering Trends and Technology (IJETT), Vol. 4, Issue 8, pp. 3544-3547, Jul 2013.

[8] Amit Sharma, Vivek Mishra, NeerajKaushik, Amit Kumar Sharma, Joshua Madhukar Singh, "Design and Simulation of Dual Band Rectangular Patch Antenna," International Journal of Electrical Electronics \& Computer Science Engineering, Vol. 1, Issue 1, pp. 8-10, Feb 2014.

[9] GurpreetKaur and Jagtar Singh, "H And T-Slotted Rectangular Microstrip Patch Antennas for Wireless Communication," International Journal of Computer Applications, Vol. 118, No. 8, pp. 40-43, May 2015. 